\title{
Proteomic analysis of human glutathione transferase omega (hGSTO1) stable transfection in a 6-hydroxydopamine-induced neuronal cells
}

\author{
Jeerang Wongtrakul ${ }^{1}$, Chonticha Saisawang ${ }^{2}$, Benjawan Kumrapich ${ }^{1}$, Jiraprapa Wipasa ${ }^{1}$, \\ Sittiruk Roytrakul ${ }^{3}$ and Albert J. Ketterman ${ }^{2}$ \\ ${ }^{1}$ Center for Molecular and Cell Biology for Infectious Diseases, Research Institute for Health Sciences, P.O. BOX 80 CMU, \\ Chiang Mai University, Chiang Mai, Thailand 50200 \\ ${ }^{2}$ Institute of Molecular Biosciences, Mahidol University, 25/25 Phutthamonthol Road 4, Salaya, Nakhon Pathom 73170, Thailand \\ ${ }^{3}$ Proteomics Research Laboratory, Genome Institute, National Center for Genetic Engineering and Biotechnology, 113 Thailand \\ Science Park, Paholyotin Road, Pathumthani 12120, Thailand
}

\begin{abstract}
Parkinson's disease is the second most common neurodegenerative disorder after Alzheimer's disease. The disease is associated with dopaminergic neuron losses in the substantia nigra area of the brain and the formation of cytoplasmic inclusion bodies. Human glutathione transferase omega 1 (hGSTO1) appears to have a role in modulating stress response. The study was aimed to elucidate differentially expressed proteins caused by oxidative stress induced by 6-hydroxydopamine (6-OHDA). Human neuronal cells SH-SY5Y overexpressing hGSTO1 were used to investigate protein glutathionylation and the modulation of cellular protein expression. Therefore SH-SY5Y/hGSTO1 and SH-SY5Y/control lysate proteins were separated by 2D-gel electrophoresis compared with untreated conditions in both standard and non-reducing conditions. In standard conditions, the analysis of protein profiles demonstrated 25 differentially expressed spots and 10 spots were chosen for further protein identification by LC-MS analysis. Several proteins were later identified as vimentin, galectin-1, high mobility group protein B2, clathrin, tropomyosin, heterogenous nuclear ribonucleoprotein and peroxiredoxin-2. Search Tool for Interactions of Chemicals (STITCH) analysis suggested that oxidative stress induced by 6-OHDA involved carbohydrate metabolism in SH-SY5Y via a lactose metabolic pathway. Our results raise the possibility that hGSTO1 modulates the functions of many proteins that play a role in the degenerative cell response of a Parkinson's model.
\end{abstract}

Key words: 6-Hydroxydopamine - Glutathione transferase omega - Proteomics - Peroxyredoxin-2 - Galectin - Vimentin - Glutathionylation

\section{Introduction}

Parkinson's disease (PD) is the second most common neurodegenerative disorder after Alzheimer's disease. The mean age of symptom onset is 62 to 70 years and is rare before age 50 with the age of peak incidence between 70 to 79 years (Muangpaisan et al. 2011). Similar peaks of incidence have been reported for populations from North America, Europe, and Australia, and an Asian population (Pringsheim et al.

Correspondence to: Albert J. Ketterman, Institute of Molecular Biosciences, Mahidol University, Salaya campus, 25/25 Phutthamonthol Road 4, Salaya, Nakhon Pathom, 73170 Thailand

E-mail: albertketterman@yahoo.com
2014). PD is characterized by a progressive degeneration of the dopaminergic neurons in a specific area of the substantia nigra in the brain. The most typical symptoms are tremor at rest, muscular rigidity, bradykinesia, postural instability and appearing in later stages, cognitive impairment including dementia (Klockgether 2004).

Glutathione transferases (GSTs E.C. 2.5.1.18) are multifunctional enzymes involved in detoxification and excretion of physiological and exogenous toxic substances (Booth et al. 1961). Mammalian GSTs have been categorized into seven classes; Alpha, Mu, Pi, Omega, Sigma, Theta and Zeta (Frova 2006). Human GST Omegas (hGSTOs) are of particular interest in this study since this isoform was differentially up-regulated in human substantia nigra protein extracted from midbrain 
specimens of Parkinson's disease patients (Werner et al. 2008) The function of hGSTO1 in neurons has not yet been elucidated. hGSTO is expressed in most tissues and possesses glutathionedependent thiol transferase activity including dehydroascorbate reductase activities (Board et al. 2000). In humans, there are two actively transcribed genes, $h$ GSTO1 and $h$ GSTO2, with both genes being located on chromosome 10q24.3 (Whitbread et al. 2005). The enzymes have been extensively characterized and found to show resistance to radiation and cytotoxic drugs as well as playing roles in response to oxidative stress (Board 2011). Several physiological functions of hGSTOs have been reported (Piaggi et al. 2010; Wongtrakul et al. 2014; Lee et al. 2015). One study showed that GSTO1 inhibits $\mathrm{H}_{2} \mathrm{O}_{2}$-mediated activation of the MAP kinase ERK (Lee et al. 2015). hGSTO appears to be involved with the activation of Akt and the MAP kinase ERK1/2 but the inhibition of JNK, another MAP kinase. In addition, drosophila omega class GST was also shown to modulate p38 kinase activity, a third type of MAP kinase (Wongtrakul et al. 2014). hGSTO has been shown to inhibit apoptosis in Hela cells transfected with hGSTO1 then treated with cisplatin, with the percentage of cell survival increasing approximately $60 \%$ compared to control cells (Piaggi et al. 2010).

In the present study, we compared the effects of a stable transfection of hGSTO1 and a vector control in the human neuronal cell SH-SY5Y in the presence of the known oxidative stress inducer 6-hydroxydopamine (6-OHDA). The cytotoxicity of 6-OHDA has been known for decades to occur through several mechanisms that generate oxidative stress (see review and papers therein, Simola et al. 2007). The 6-OHDA induces oxidative stress by generating hydrogen peroxide and reactive oxygen species after an oxidation reaction thereby resulting in a rapid depletion of cellular antioxidant enzymes leading to an amplified neurotoxicity causing abnormalities in cell structure, metabolism and neuronal damage (Simola et al. 2007). Two dimensional gel electrophoresis-based proteomics was employed to determine the protein expression differences with mass spectrometric identification in the SH-SY5Y/hGSTO1 and SH-SY5Y/control vector only cells under 6-OHDA-induced oxidative stress. In addition, by $2 \mathrm{D}$-immunoblotting we also identified glutathionylated protein changes in response to 6-OHDA induced oxidative stress. Glutathionylation has been shown to effect modified proteins with consequences such as inhibition or activation of biological activity similar to phosphorylation of proteins (Dalle-Donne et al. 2009).

\section{Materials and Methods}

\section{Cell culture}

The SH-SY5Y (ATCC ${ }^{\circledast}$ CRL-2266 ${ }^{\mathrm{mm}}$ ) cell line was obtained from American Type Culture Collection (ATCC). Cells were maintained in Dulbecco's modified Eagle's medium (DMEM)/F12 (Gibco, Invitrogen, USA) containing 15\% fetal bovine serum (FBS; Gibco, Invitrogen, USA) with $50 \mathrm{U} /$ $\mathrm{ml}$ penicillin, $50 \mu \mathrm{g} / \mathrm{ml}$ streptomycin and $1 \%$ non-essential amino acids (Gibco, Invitrogen, USA) at $37^{\circ} \mathrm{C}$ and incubated in a humidified atmosphere with $95 \%$ air $/ 5 \% \mathrm{CO}_{2}$.

\section{Construction of hGSTO1 lentiviral expression vectors}

Total RNA was extracted from SH-SY5Y cells and converted to cDNA by reverse transcription. The cDNA was employed as template to amplify $h G S T O 1$ using forward primer 5' TATACTCGAGATGTCCGGGGAGTCAG 3' and reverse primer 5' CTAGGATCCTCAGAGCCCATAGTCAC 3'. The hGSTO1 was digested with XhoI and BamHI restriction enzymes and inserted into pLVX-Puro vector (Clontech). pLVX-Puro is a vector for viral transduction. The recombinant plasmids were randomly screened by restriction analysis then the nucleotide sequences of the plasmids were verified by full-length sequencing in both directions.

\section{Generating stable cell lines by viral transduction}

HEK293T cells were used as a host cell for viral production. The cells were grown in DMEM media supplemented with $10 \%$ FBS and penicillin-streptomycin antibiotic. The cells were incubated at $37^{\circ} \mathrm{C}, 5 \% \mathrm{CO}_{2}$. To produce viral supernatant, HEK293T cells were plated in $100 \mathrm{~mm}$ tissue culture plates overnight. The cells were $80-90 \%$ confluent at the time of transfection. Then $1 \mu \mathrm{g} / \mu \mathrm{l}$ empty pLVX vector and hGSTO1 in pLVX vector DNAs were co-transfected with viral packaging mix into HEK293T cells. After overnight incubation, the transfection medium was replaced with $10 \mathrm{ml}$ fresh complete growth medium (containing Tet System Approved FBS) and incubate at $37^{\circ} \mathrm{C}$ for an additional 24 hours. The virus supernatant was harvested by filtering through a $0.45 \mu \mathrm{m}$ filter to remove cellular debris. The lentiviral supernatants produced by the transfected packaging cells were then used to infect and transduce SH-SY5Y cells to express the $h G S T O 1$ gene. The virus production was verified with Lenti-X Go-Stix ${ }^{\text {TM }}$ and stored at $-80^{\circ} \mathrm{C}$. SH-SY5Y cells were plated in $100 \mathrm{~mm}$ plates $12-18 \mathrm{~h}$ before transduction with prepared virus. The virus supernatant was mixed with media 1:3 ratio including $4 \mu \mathrm{g} / \mu \mathrm{l}$ of polybrene, added to the cells and transduced for $24 \mathrm{~h}$. After that the virus was removed and replaced with fresh growth media. The cells were incubated for $24-48 \mathrm{~h}$ to allow the $h$ GSTO1 gene product to accumulate in the target cells.

\section{6- OHDA treatment and percent cell survival}

6-Hydroxydopamine hydrobromide (contains ascorbic acid as stabilizer > 98\%), HPLC grade, (Sigma, St. Louis, MO) 
was used as a $10 \mathrm{mM}$ stock solution in 1X PBS (phosphate buffered saline, $\mathrm{pH}$ 7.4, Sigma, St. Louis, MO). To determine percent cell survival of SH-SY5Y/hGSTO1 and SH-SY5Y/ control under treatment conditions with 6-OHDA, CellTiter $96^{\circ}$ AQueous One Solution Cell Proliferation Assay (Promega) was employed following the manufacturer's instructions. SH-SY5Y/hGSTO1, and SH-SY5Y/control were plated in 96-well plates overnight and treated with varying concentrations of 6-OHDA for 24 hours. At the end of treatment, supernatant was removed and replaced with $100 \mu \mathrm{l}$ of DMEM/F12 containing 5\% serum. Then $20 \mu$ of MTS reagent was added to each well and after an additional 4 hours of incubation, the color was monitored at $490 \mathrm{~nm}$ (spectra MR microplate spectrophotometer, DYNEX technologies). Percent cell survival was calculated by using an OD measured from untreated conditions as 100 percent survival.

\section{Protein extraction and 2-D electrophoresis}

SH-SY5Y/control and SH-SY5Y/hGSTO1 cells were harvested and resuspended with $100 \mu \mathrm{l}$ of Lysis buffer (8 M urea, $2 \mathrm{M}$ thiourea, 4\% CHAP, $50 \mathrm{mM}$ DTT and $1 \mathrm{mM}$ PMSF), for non-reducing conditions thiourea and DTT were omitted. The cells were then sonicated using a sonicator with amplitude level 6 for $5 \mathrm{~s}$ and pulse for $10 \mathrm{~s}$ twice before centrifugation at $12,000 \times g$ for $15 \mathrm{~min}$ at $4^{\circ} \mathrm{C}$. Then the cell lysate was transferred to a new tube and $200 \mu \mathrm{l}$ pre-chilled methanol and $600 \mu \mathrm{l}$ pre-chilled acetone was added. The tube was then vigorously vortexed and stored at $-70^{\circ} \mathrm{C}$ overnight. The tubes were centrifuged at $12,000 \times g$ for $15 \mathrm{~min}$ at $4^{\circ} \mathrm{C}$. Supernatant was discarded and $1 \mathrm{ml}$ pre-chilled acetone was added. The tube was centrifuged again and supernatant was discarded. The pellet was air dried and dissolved in Lysis buffer. Protein was quantified by Bradford assay. First dimension isoelectrofocusing (IEF) was performed using an $18 \mathrm{~cm}$ Immobiline ${ }^{\mathrm{TM}}$ DryStrip pH 3-10 nonlinear. Strips were actively rehydrated in the presence of $200 \mu \mathrm{g}$ of each sample for $12 \mathrm{~h}$ in an IPGphor system (Amersham Biosciences/GE Healthcare). Focusing was performed at $20^{\circ} \mathrm{C}$, at $50 \mu \mathrm{A} / \mathrm{IPG}$ strip as follows: 1 ) $300 \mathrm{~V}$ for $200 \mathrm{Vhr}, 2) 1000 \mathrm{~V}$ for $300 \mathrm{Vhr}, 3) 3000 \mathrm{~V}$ for 4000 Vhr, 4) $5000 \mathrm{~V}$ for $4500 \mathrm{Vhr}$, and 5) $5000 \mathrm{~V}$ for $3000 \mathrm{Vhr}$ until 12000 Vhr was reached in total. After IEF, IPG-strips were equilibrated in a buffer containing $6 \mathrm{M}$ urea, $30 \%(\mathrm{v} / \mathrm{v})$ glycerol, 2\% (w/v) SDS, 75 mM Tris- $\mathrm{HCl}(\mathrm{pH} 8.8), 50 \mathrm{mM}$ DTT and $0.002 \%(\mathrm{w} / \mathrm{v})$ bromophenol blue for $15 \mathrm{~min}$, for non-reducing conditions DTT was not added. Then the strips were equilibrated in buffer containing $130 \mathrm{mM}$ iodoacetamide for $15 \mathrm{~min}$. SDS-PAGE (second dimension) was performed using $12.5 \%$ acrylamide/bis-acrylamide. After electrophoresis the gel was stained with Colloidal Coomassie Blue, for non-reducing conditions an additional gel was made and transferred to a PVDF membrane for Western blot detection of glutathionylated protein spots.

\section{Protein identification}

Differentially expressed protein spots were removed and subjected to in-gel tryptic digestion according to the method from (Paemanee et al. 2016). The peptide mixtures were analyzed by Dionex Ultimate 3000 (Thermo Scientific) in combination with an electrospray ionization (ESI)/quadrupole ion trap mass spectrometer (amaZon SL, Bruker Daltonik, Germany). The LC separation was performed on a reverse phase column (Hypersil GoLD $50 \times 0.5 \mathrm{~mm}, 5 \mu \mathrm{m} \mathrm{C18}$ ), protected by a guard column, eluted at a flow rate of $100 \mu \mathrm{l} /$ min under gradient conditions of $5-80 \%$ B over $50 \mathrm{~min}$. Mobile phase A consists of water/formic acid (99.9:0.1, v/v), and $\mathrm{B}$ consists of acetonitrile $(100 \%, \mathrm{v})$. The mass spectral data from $150 \mathrm{~m} / \mathrm{z}$ to $1500 \mathrm{~m} / \mathrm{z}$ were collected in the positive ionization mode. The MS/MS spectrometry data were searched against the NCBI database using the MASCOT search engine, as described elsewhere (Paemanee et al. 2016).

\section{Immunoblot analysis}

Proteins were separated under standard conditions on $12.5 \%$ SDS-polyacrylamide gels and transferred to PVDF solid matrix support (Amersham Hybond-P, GE Healthcare). Nonspecific binding was reduced by incubating the membrane in Blocking Buffer which was $25 \mathrm{mM}$ Tris- $\mathrm{HCl}$, pH 8.3, 192 mM glycine, 20\% methanol, 0.1\% SDS and 5\% skimmed milk at $4^{\circ} \mathrm{C}$ for $1 \mathrm{~h}$. Membranes were incubated with specific antibodies (in Blocking Buffer) overnight at $4^{\circ} \mathrm{C}$, washed three times with TBST for $10 \mathrm{~min}$, and incubated with the appropriate secondary antibody conjugated to horseradish peroxidase for $1 \mathrm{~h}$. The membranes were washed three times and developed with Luminata Forte Western HRP Substrate (Merck KGaA, Darmstadt, Germany) detection system, according to the manufacturer's instructions. GAPDH was employed as an internal control. Image J software was employed to determine optical density values of bands for relative comparisons. The experiments were performed in triplicate.

\section{Antibodies}

Antibodies were purchased from the following sources: anti-Peroxiredoxin 2 antibody used at 1/1000 dilution (abcam), anti-Galectin 1 antibody used at 1/1000 dilution (Thermo scientific), anti-Vimentin antibody used at $1 / 1000$ dilution (Thermo scientific), anti-Glutathione antibody [D8] used at 1/1000 dilution or 1/2000 (abcam), anti-glutathione transferase Omega 1 used at 1/1000 dilution (abcam) and anti-GAPDH used at 1/1000 dilution (Cell Signaling Technology). The secondary antibodies used were a goat anti-rabbit IgG-HRP used at 1/2000 or 1/5000 dilution (Santa Cruz Biotechnology) and a goat 
anti-mouse IgG peroxidase used at $1 / 5000$ or $1 / 12000$ dilution (Sigma-Aldrich).

\section{Statistical analysis}

The data were expressed as mean \pm SEM. The expression level of proteins and the intensity of the bands were compared using unpaired $t$-test, Prism 5 software. $p$ values less than 0.05 were considered statistically significant.

\section{Results}

Overexpression of hGSTO1 in SH-SY5Y cells increases cell viability

Human neuronal cells SH-SY5Y were stably transfected with pLVX vector encoding hGSTO1 and the PLVX vector alone as control. The stable cell lines were selected with $2 \mu \mathrm{g} / \mathrm{ml}$ of puromycin antibiotic for 4 to 7 days. The media were changed every 2 days to remove dead cells. To detect hGSTO1 expression of transduced SH-SY5Y/ hGSTO1, western blot analyses was performed 7 days after cells were transfected. As shown in Figure 1A and 1B, the SH-SY5Y cells transfected with hGSTO1 showed a significant increase in hGSTO1 expression. Figure 1C showed protection against cytotoxicity of increasing concentrations of 6-OHDA administered to SH-SY5Y/hGSTO1 in comparison to SH-SY5Y/control. Twenty-four hours after treatment with 6-OHDA, from 0 to $1000 \mu \mathrm{M}$, the survival of SH-SY5Y/hGSTO1 was significantly different from SHSY5Y/control at $250 \mu \mathrm{M}$ and $333.3 \mu \mathrm{M}$ concentrations. The survival of SH-SY5Y/hGSTO1 was greatest with a maximum difference at the concentration of $250 \mu \mathrm{M}$ 6-OHDA with $97 \%$ survival as compared to $62 \%$ in SH-SY5Y/control cells. At $333.3 \mu \mathrm{M}$, percent survival of SH-SY5Y/hGSTO1 was approximately 1.91 -fold greater than $\mathrm{SH}-\mathrm{SY} 5 \mathrm{Y} /$ control cells. Therefore the concentration of $250 \mu \mathrm{M}$ was chosen for further experiments since it demonstrated the greatest difference between the two constructs.

\section{6-OHDA induced proteomic alteration in SH-SY5Y}

2D gel electrophoresis performed in triplicate with $\mathrm{SH}-\mathrm{SY} 5 \mathrm{Y} /$ control and SH-SY5Y/hGSTO1 treated with 6-OHDA for 2 hours were compared with untreated SH-SY5Y/control
A

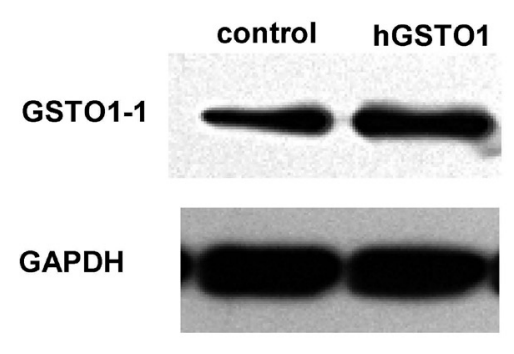

B

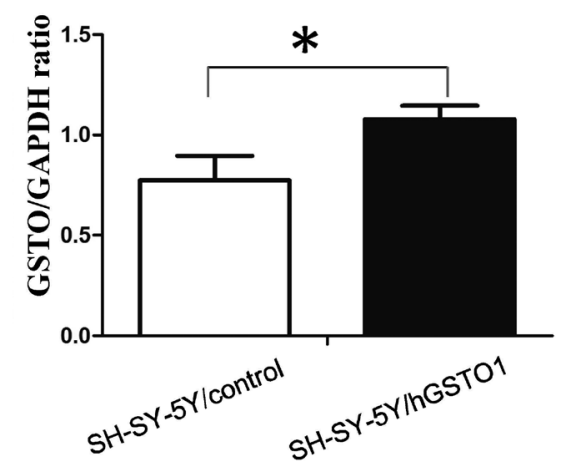

C

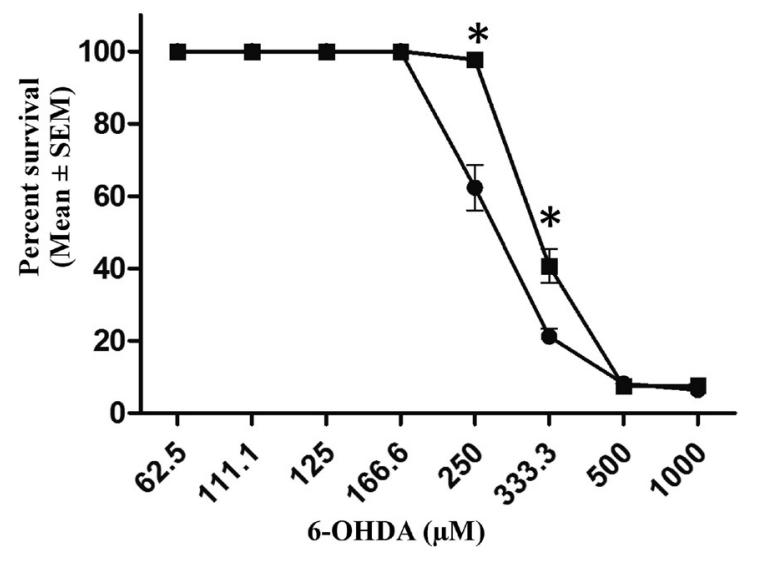

Figure 1. The expression levels of hGSTO1 in SH-SY5Y and effects of hGSTO1 expression on 6-OHDA cytotoxicity. Cells transfected with hGSTO1 and the empty vector were cultured for one week before harvesting. A. Representative immunoblots show the expression of hGSTO1 in SH-SY5Y cells. B. Comparison of differences in the expression levels of hGSTO1 between SH-SY5Y/control and SH-SY5Y/ hGSTO1. Quantitative data indicated that the expression of hGSTO1 protein extracted from SH-SY5Y/hGSTO1 was slightly higher than protein extracted from SH-SY5Y/control. Data are mean \pm SEM of two experiments performed in triplicate. C. SH-SY5Y/hGSTO1 and SHSY5Y/control cells were treated for $24 \mathrm{~h}$ with increasing concentrations of 6-OHDA. Cell survival was determined by MTS assay, as described in Materials and Methods. Data are mean \pm SEM of at least five experiments performed in duplicate. Data were analyzed by Unpaired $t$-test; ${ }^{*} p<0.05$; SH-SY5Y/control; $\bullet \mathrm{SH}-\mathrm{SY} 5 \mathrm{~S} / \mathrm{hGSTO}$. 
and SH-SY5Y/hGSTO1. Twenty-five protein spots were found to be differentially expressed between the four groups ( $p$ values $<0.05)$. The data were normalized by calculating the ratio of treated/untreated for control and hGSTO1. The criteria to define significant changes in protein abundance is the ratio of the normalized hGSTO1 compared to the ratio of normalized control which must be either greater than 1.5 -fold (significant increase) or less than 0.67 (significant decrease). Overall, there were 7 proteins significantly down-regulated (spot 504, 1, 421, 217, 255, 579 and 582), 3 proteins significantly up-regulated (spot 100, 350 and 859) (Figure 2A and $2 \mathrm{~B})$ and 15 proteins which showed no differences. 10 protein spots were selected and identified by mass spectrometry: vimentin, galectin-1, high mobility group protein $\mathrm{B} 2$, clathrin light chain A isoform a, skeletal muscle tropomyosin, heterogeneous nuclear ribonucleoprotein, peroxiredoxin-2 and unnamed protein product (Table 1). The predicted and experimental values of the isoelectric point (pI), molecular weight (MW), and the relative expression levels for the identified proteins are summarized in Table 1.

\section{Verification of proteomic analysis}

To validate the results of the $2 \mathrm{D}$ analysis, three proteins were selected for further analysis, namely vimentin, peroxyredoxin- 2 and galectin. All protein quantities were subsequently normalized to the loading control GAPDH. To compare between hGSTO1 and vector control, the ratio of treated/untreated data was calculated and shown in Figure 3. SH-SY5Y/ hGSTO1 and SH-SY5Y/control cells were therefore treated with 6-OHDA at a final concentration at $250 \mu \mathrm{M}$ in parallel, with untreated cells of SH-SY5Y/hGSTO1 and SH-SY5Y/ control as their own respective baseline. The results shown in Figure 3 confirmed the proteomic analysis for the three

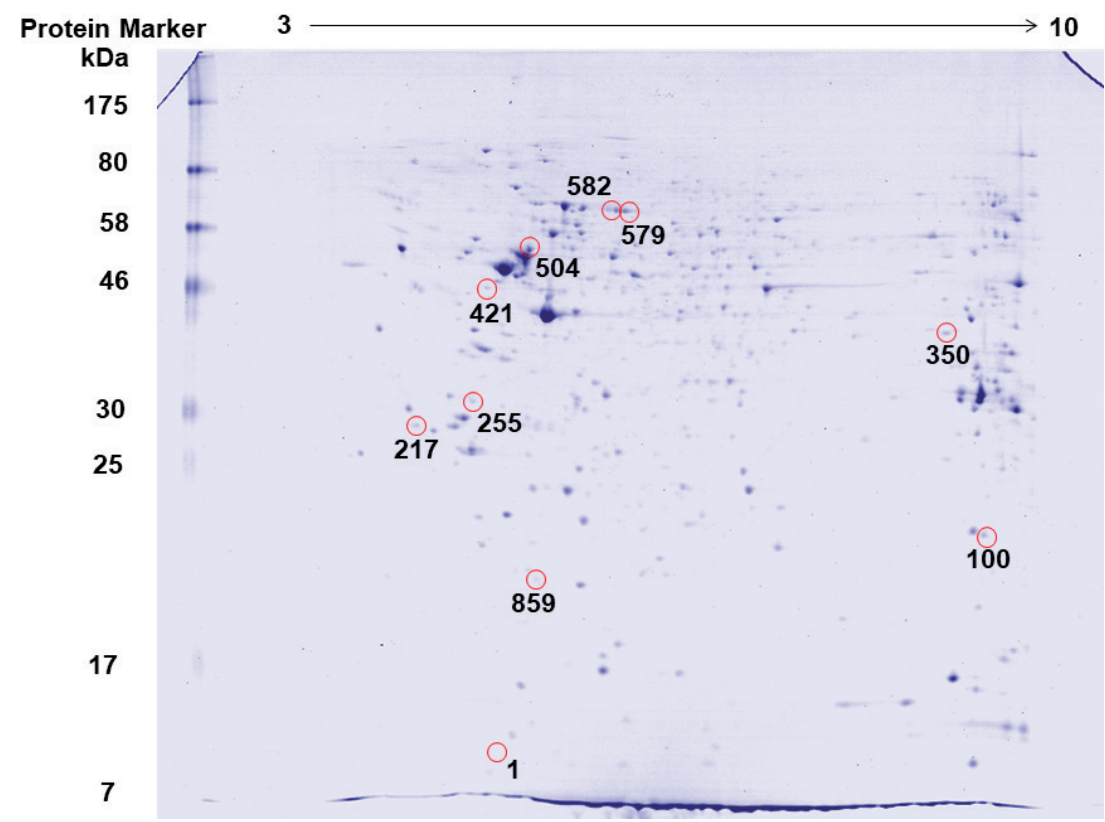

B

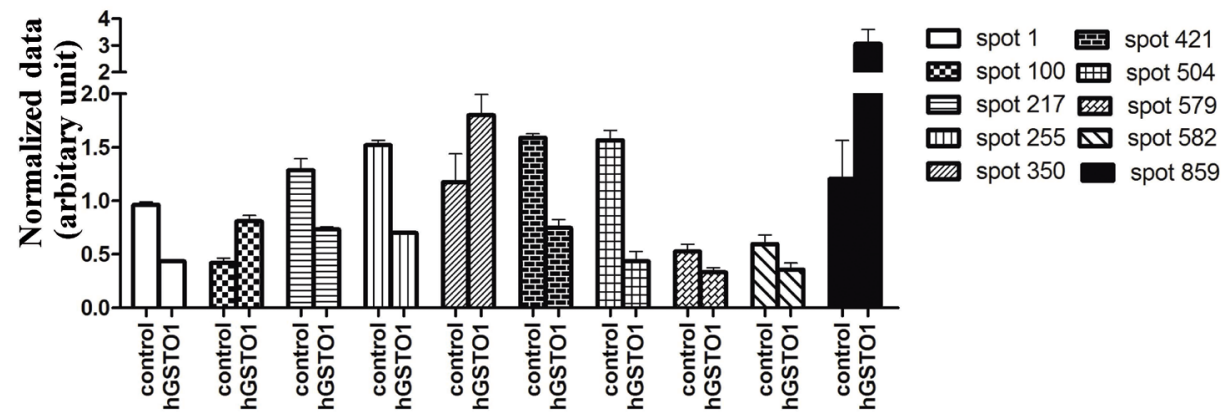

Figure 2. Location of 10 selected differential expressed spots in the 2D gel of SH-SY5Y/control master map. A. $200 \mu \mathrm{g}$ proteins were loaded onto $18 \mathrm{~cm}$ strip $\mathrm{pH}$ 3-10 NL. B. Normalized data of 10 differential expressed proteins. Data are mean \pm SEM of three replicates. The expression level of proteins and the intensity of the bands were compared using unpaired $t$-test, Prism 5 software. $p$ values less than 0.05 were considered statistically significant. 
Table 1. Differentially expressed proteins in the lysate protein obtained from SH-SY5Y/control and SH-SY5Y/hGSTO1 treated with $250 \mu \mathrm{M}$ 6-OHDA for 2 hours, identified by LC/MS

\begin{tabular}{|c|c|c|c|c|c|c|}
\hline $\begin{array}{l}\text { Spot } \\
\text { number }\end{array}$ & $\begin{array}{l}\text { Accession } \\
\text { number }\end{array}$ & Protein name & $\begin{array}{c}\text { Nominal } \\
\text { mass }\left(M_{r}\right)\end{array}$ & $\begin{array}{c}\text { Calculated pI } \\
\text { value }\end{array}$ & $\begin{array}{c}\text { Protein } \\
\text { score }\end{array}$ & $\begin{array}{c}\text { Sequence } \\
\text { coverage (\%) }\end{array}$ \\
\hline \multicolumn{7}{|c|}{ Response to stress } \\
\hline 1 & $\mathrm{sp} \mid \mathrm{P} 09382$ & Galectin- $1 \downarrow$ & 15048 & 5.34 & 95 & $25 \%$ \\
\hline 859 & $\mathrm{sp} \mid \mathrm{P} 32119$ & Peroxiredoxin- $2 \uparrow$ & 2049 & 5.66 & 74 & $21 \%$ \\
\hline \multicolumn{7}{|c|}{ Cytoskeleton } \\
\hline 255 & gi|339958 & skeletal muscle tropomyosin, partial $\downarrow$ & 26573 & 4.64 & 86 & $13 \%$ \\
\hline 421 & $\mathrm{sp} \mid \mathrm{P} 08670$ & Vimentin $\downarrow$ & 53676 & 5.06 & 73 & $9 \%$ \\
\hline 504 & $\mathrm{sp} \mid \mathrm{P} 08670$ & Vimentin $\downarrow$ & 53676 & 5.06 & 135 & $22 \%$ \\
\hline \multicolumn{7}{|c|}{ Transcription } \\
\hline 100 & gi|11321591 & high mobility group protein $\mathrm{B} 2 \uparrow$ & 24190 & 7.62 & 42 & $10 \%$ \\
\hline 350 & sp|Q14103 & Heterogeneous nuclear ribonucleoprotein D0 $\uparrow$ & 38581 & 7.62 & 43 & $4 \%$ \\
\hline \multicolumn{7}{|l|}{ Transport } \\
\hline 217 & gi|4502899 & clathrin light chain A isoform a $\downarrow$ & 23704 & 4.45 & 116 & $15 \%$ \\
\hline \multicolumn{7}{|l|}{ Unknown } \\
\hline 579 & gi|28590 & unnamed protein product $\downarrow$ & 71246 & 5.92 & 77 & $3 \%$ \\
\hline 582 & gi| 28590 & unnamed protein product $\downarrow$ & 71246 & 5.92 & 73 & $4 \%$ \\
\hline
\end{tabular}

proteins, with vimentin and galectin being down regulated and peroxyredoxin-2 being up regulated after 6-OHDA treatment. To elucidate the association between differentially expressed proteins and the metabolites reported, 8 identified proteins from Table 1 were subjected to a pathway analysis to query each protein relative to the other identified proteins in the database using STITCH (Search Tool for Interactions of Chemicals, http://stitch.embl.de/). The STITCH analysis of the Homo sapiens database revealed that 6-OHDA induces neuronal cell response to produce differentially expressed proteins similar to the stimulation by hydrogen peroxide via mechanisms that employed calcium and lactose (Figure 4).

\section{hGSTO1 affected intracellular glutathionylation of SH-SY5Y} induced with 6-OHDA

Protein S-glutathionylation was investigated using an anti-GSH antibody. A time course of glutathionylation was performed in SH-SY5Y/hGSTO1 and SH-SY5Y/control cells by treatment with $250 \mu \mathrm{M}$ 6-OHDA for $0,15,30,60$ and 120 minutes. In addition, hGSTO1 protein expression was also monitored. The data demonstrated that a $250 \mu \mathrm{M}$ 6-OHDA treatment in control and hGSTO1 transfected cells results in an increase of S-glutathionylation of a variety of proteins (Figure 5A and $5 \mathrm{~B}$ ). The size of the major glutathionylated protein band was approximately $45 \mathrm{kDa}$ which was most likely actin and was found in both control and hGSTO1 transfected cells. Therefore, this band was selected for the relative quantitation of glutathionylated proteins by normalization with GAPDH. Glutathionylation of proteins in control and hGSTO1 cells increased within 15 min and peaked at $30 \mathrm{~min}$ then decreased at 60 and $120 \mathrm{~min}$ respectively (Figure 5). At 15 and $30 \mathrm{~min}$, glutathionylated proteins in the control were at significantly greater amounts than in the hGSTO1 transfected cells. The amount of GST omega protein was monitored by Western blot. The signal intensity of hGSTO1 in SH-SY5Y/hGSTO1 cells was greater than control at every time point from 0 to $120 \mathrm{~min}$ and significantly greater than control at the $30 \mathrm{~min}$ time point. Increased expression of hGSTO1 seemed to be associated with decreased glutathionylation under treatment conditions. Therefore the time of $30 \mathrm{~min}$ treatment was chosen to further identify glutathionylated proteins by $2 \mathrm{D}$ gel electrophoresis immunoblotting using non-reducing conditions.

\section{Identification of S-glutathionylated proteins}

6-OHDA treatment leads to rapid S-glutathionylation of many proteins in SH-SY5Y cells. To elucidate the biological importance, $200 \mu \mathrm{g}$ of whole lysates were extracted from SH-SY5Y/control and SH-SY5Y/hGSTO1 after 30 min treatment with $250 \mu \mathrm{M}$ 6-OHDA. Then the extracts were separated by non-reducing two-dimensional SDSPAGE and compared to untreated samples prepared in parallel. The Coomassie-stained gels of treated and untreated cells of SH-SY5Y/control and SH-SY5Y/hGSTO1 show equivalent protein loading (Figure 6A and 6B, Figure $7 \mathrm{~A}$ and $7 \mathrm{~B})$. S-glutathionylated proteins were detected in $\mathrm{SH}-\mathrm{SY} 5 \mathrm{Y} / \mathrm{control}$ from both treated and untreated conditions (Figure 6C and 6D). Two of the proteins were excised from the gel, digested with trypsin, and identified by mass-spectrometry (Table 2). The predicted and experi- 
A

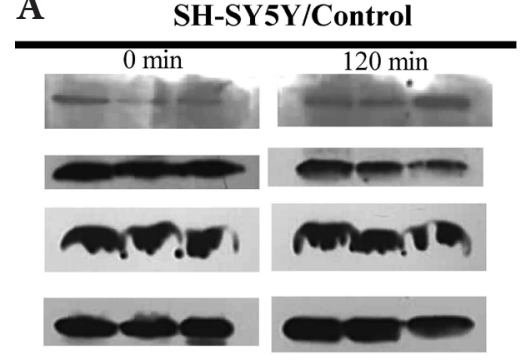

B
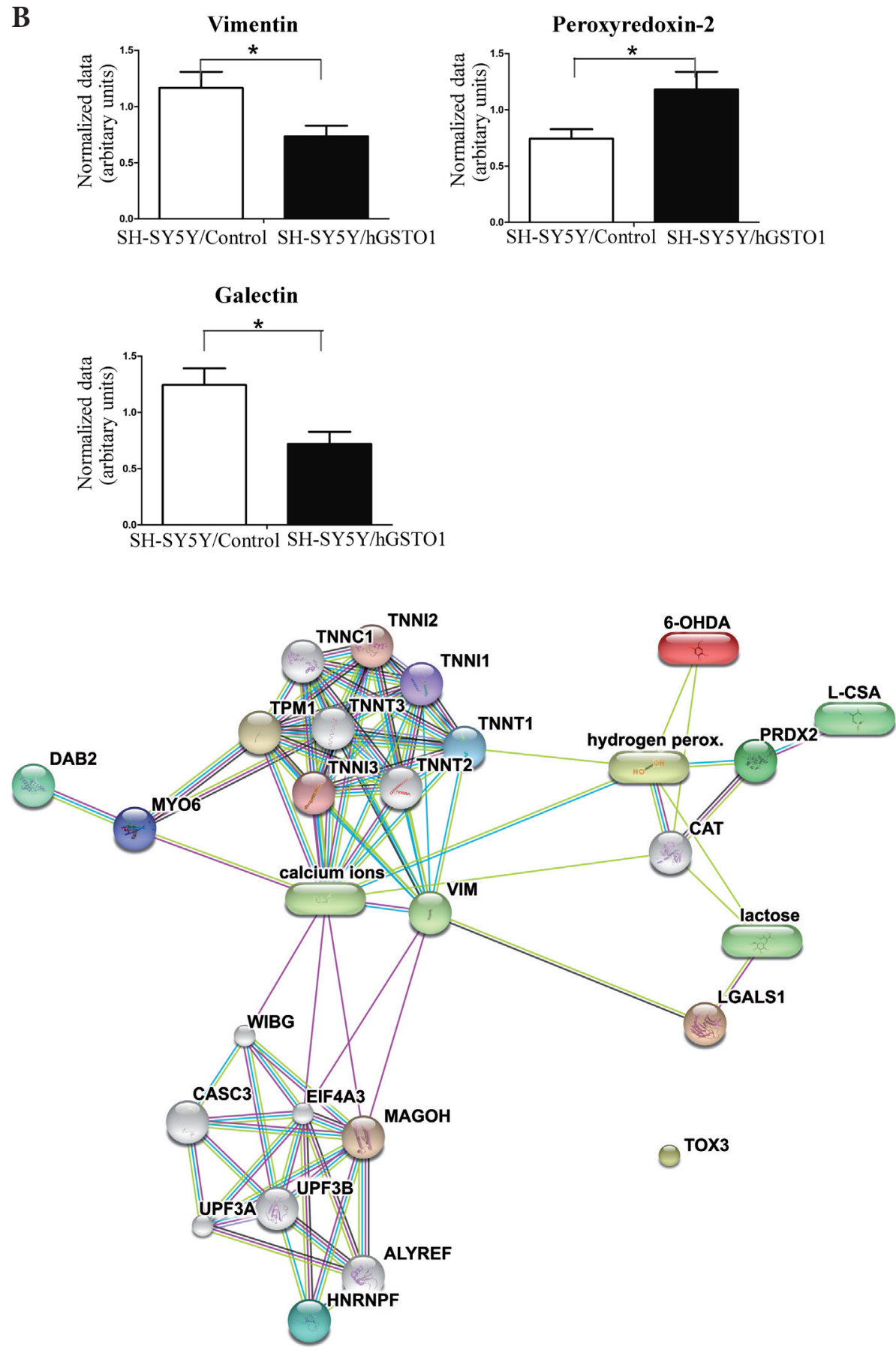

Figure 3. The Western blot analysis of vimentin, peroxyredoxin-2 and galectin. A. SH-SY5Y/control and SH-SY/hGSTO1 were not treated $(0 \mathrm{~min})$ or treated with $250 \mu \mathrm{M}$ 6-OHDA (120 min). After $120 \mathrm{~min}$ utes of treatment cell lysates were prepared which were subjected to SDS-PAGE and Western blot analysis to detect the expression of vimentin, peroxyredoxin-2, galectin and glyceraldehyde-3-phosphate dehydrogenase (GAPDH). The experiment was performed independently in triplicate. B. Protein band intensities were quantitated using the imageJ image analysis program and analyzed by GraphPad Prism 5 program and the expression of all proteins were normalized to GAPDH. Error bars show S.E.M.

Figure 4. Analysis of proteins differentially expressed in 6-OHDAtreated SH-SY5Y. STITCH analysis of proteins differentially expressed in response to 6-OHDA treatment. The nodes (balls) indicate proteins with the lines representing predicted associations with the proteins identified in this study. The line colors show the evidence used for prediction: red line, indicates the presence of fusion evidence; green line, neighborhood evidence; blue line, occurrence evidence; purple line, experimental evidence; yellow line, textmining evidence; light blue line, database evidence; black line, coexpression evidence (Search Tool for Interactions of Chemicals, http:// stitch.embl.de/) (See online version for color figure). 
A
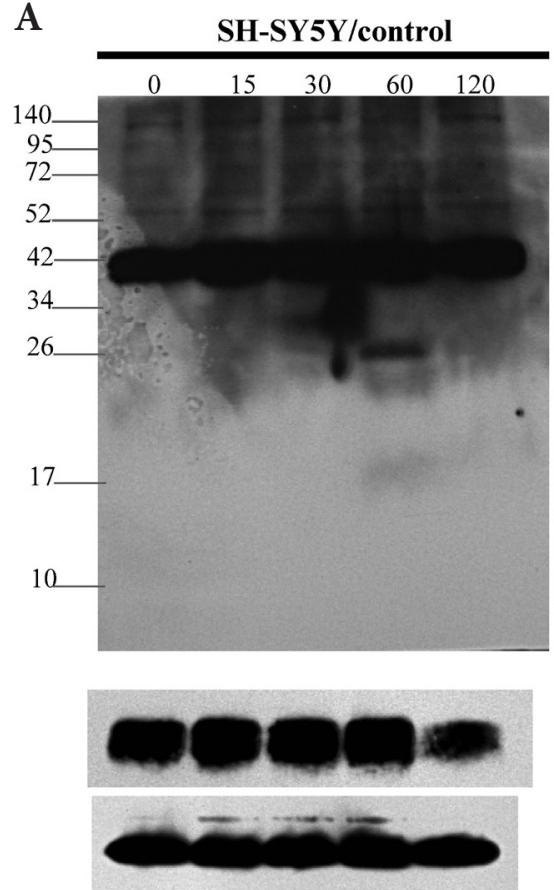

IB: PSSG

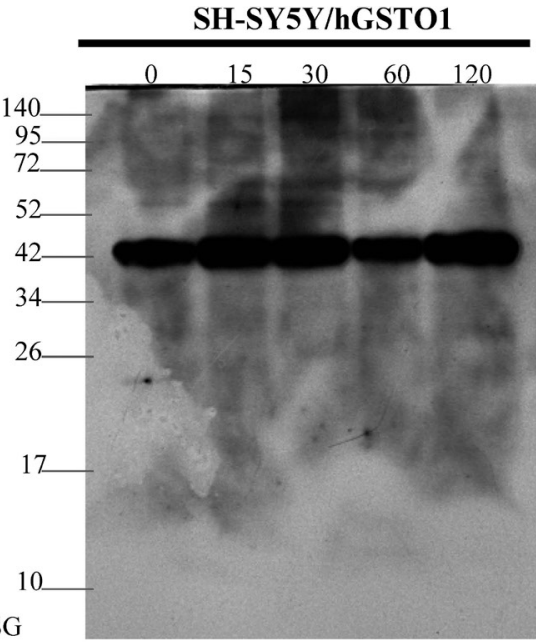

IB: omega GS

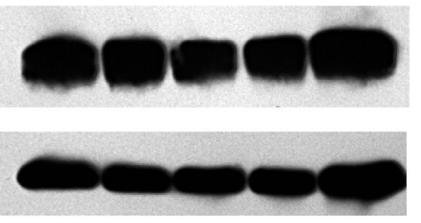

IB: GAPDH

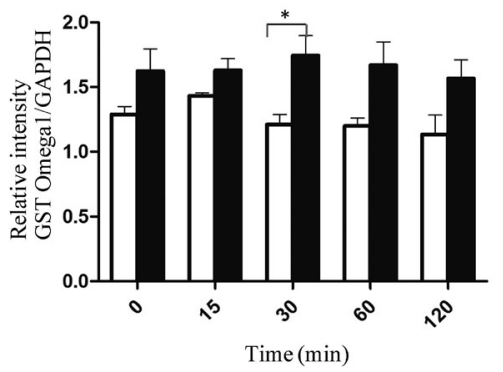

Figure 5. S-glutathionylation in SHSY5Y cells over-expressing hGSTO1. A. Empty vector (left) and hGSTO1 cells (right) were treated with $250 \mu \mathrm{M}$ 6-OHDA for 0 to $120 \mathrm{~min}$. Proteins were separated by non-reducing SDS-PAGE and S-glutathionylation was evaluated by immuno blot with anti-GSH antibody. Omega GST expression was detected with anti-GST omega antibody and the loading of protein was confirmed by stripping the membrane and re-probing for GAPDH. The experiment was undertaken independently in triplicate. B. Protein band intensities of GSSG/ GAPDH (left), and omega GST/ GAPDH (right) were quantitated using the imageJ image analysis program and analyzed by GraphPad Prism 5 program and the expression of all proteins was normalized to GAPDH. Error bars show S.E.M. $\square \mathrm{SH}-\mathrm{SY} 5 \mathrm{Y} /$ control; - SH-SY5Y/ hGSTO1. mental values of isoelectric point (pI), molecular weight (MW), as well as the score for the identified proteins are summarized in Table 2. The comparison between the untreated and the $30 \mathrm{~min}$ treatment of SH-SY5Y/control revealed that ATP synthase (spot 1, Figure 6C and 6D) is down-regulated with decreased expression levels of less than 0.76-fold compared to untreated cells. Limk1 Mutant D460n protein (spot 2, Figure 6D) was detected only in the treated cells. In the SH-SY5Y/hGSTO1 untreated and 30 min treatment cells, Vimentin (spot 1, Figure 7C and 7D) was up-regulated with increased expression levels of more than 1.24-fold compared to the untreated cells.

Table 2. MALDI-TOF identification of S-glutathionylated proteins in SH-SY5Y/control and SH-SY5Y/hGSTO1 treated with $250 \mu \mathrm{M}$ 6-OHDA for $30 \mathrm{~min}$, identified by LC/MS

\begin{tabular}{|c|c|c|c|c|c|}
\hline $\begin{array}{l}\text { Spot } \\
\text { number }\end{array}$ & $\begin{array}{l}\text { Accession } \\
\text { number }\end{array}$ & Description & $\begin{array}{l}\text { Nominal } \\
\text { mass }\left(M_{r}\right)\end{array}$ & $\begin{array}{l}\text { Calculated } \\
\text { pI value }\end{array}$ & $\begin{array}{c}\text { Protein } \\
\text { score }\end{array}$ \\
\hline \multicolumn{6}{|c|}{ SH-SY5Y/control } \\
\hline 1 & gi32189394 & ATP synthase subunit beta, mitochondrial precursor [Homo sapiens] & 56525 & 5.26 & 329 \\
\hline 2 & gi1025735596 & $\begin{array}{l}\text { Chain B, crystal structure of limk1 mutant D460n in complex with } \\
\text { full-length cofilin-1 }\end{array}$ & 18642 & 8.26 & 138 \\
\hline \multicolumn{6}{|c|}{ SH-SY5Y/hGSTO1 } \\
\hline 1 & gi47115317 & VIM, partial [Homo sapiens] & 53547 & 5.08 & 678 \\
\hline
\end{tabular}


A

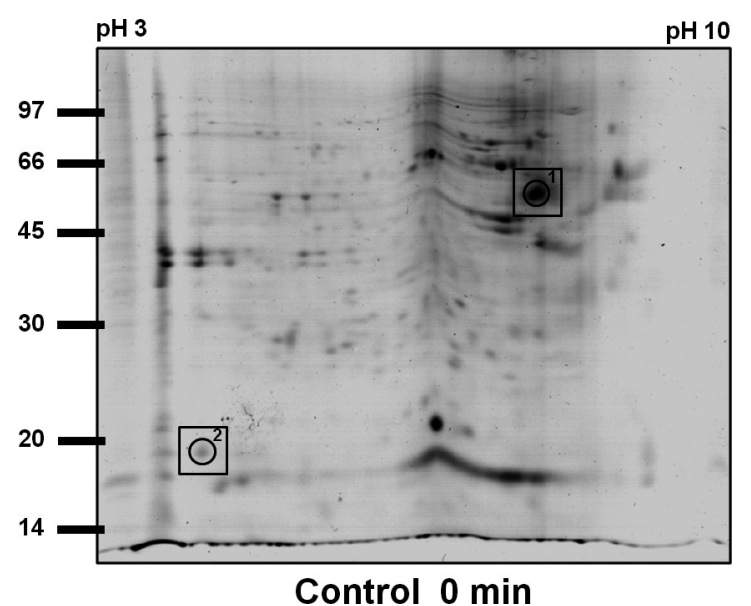

C

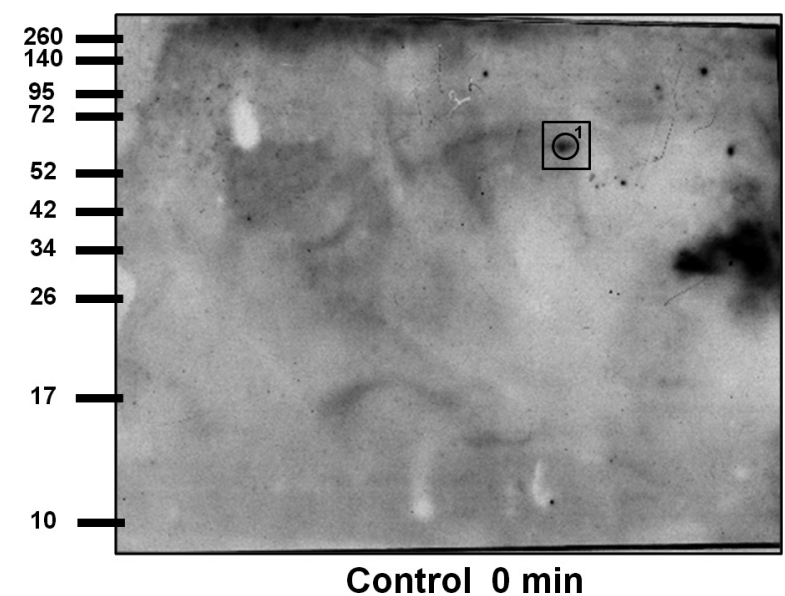

B

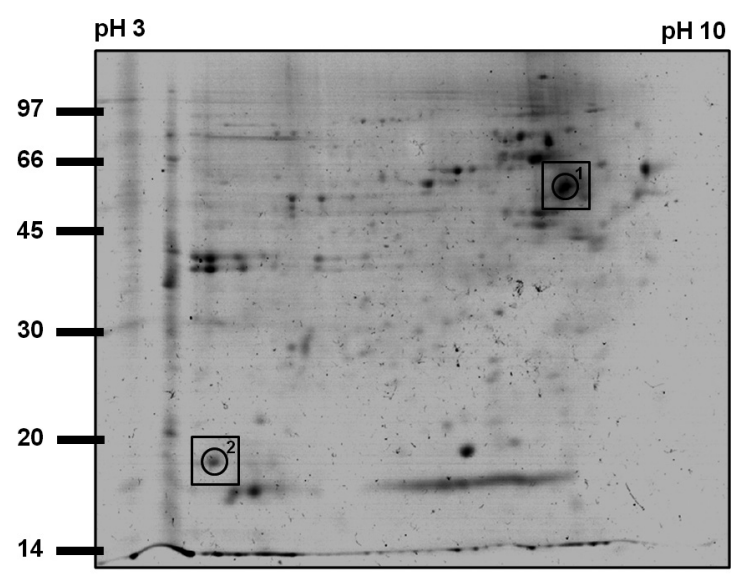

Control $30 \mathrm{~min}$

D

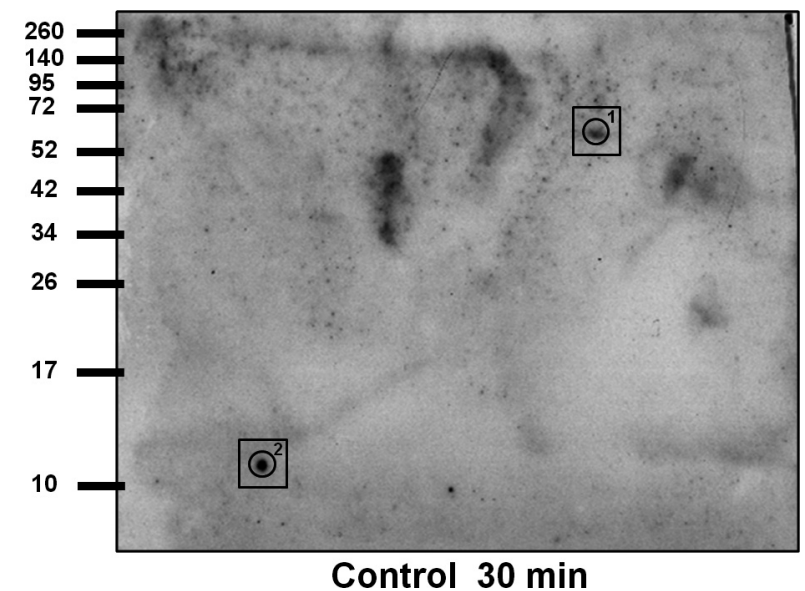

Figure 6. Two-dimension analysis of SH-SY5Y/control untreated (C) and treated (D) with $250 \mu \mathrm{M}$ 6-OHDA. Two hundred micrograms of protein lysate were separated under non-reducing conditions and immunoblotted with the anti-GSH antibody. Coomassie-stained gels of untreated (A) and treated (B) represent equivalent loading.

\section{Discussion}

The human neuronal cell line SH-SY5Y was employed in this study to determine a physiological contribution of hGSTO1 during the oxidative stress induced by 6-OHDA. Stable transfected SH-SY5Y/hGSTO1 and SH-SY5Y/control were generated for use in the study of hGSTO1. The percent cell survival, 2D-gel electrophoresis, protein identification and the role of hGSTO1 in glutathionylation were studied.

The study shows that hGSTO1 over-expression can efficiently protect $\mathrm{SH}-\mathrm{SY} 5 \mathrm{Y}$ cells against 6-OHDA-induced oxidative stress. The results obtained in the cytotoxicity experiment showed that the highest protection was apparent at the concentration of $250 \mu \mathrm{M} 6$-OHDA, where a $97 \%$ survival was observed in over-expressing hGSTO1 cells as compared with only $62 \%$ in controls (Figure
1C). A similar role of hGSTO1 in the protection of neuronal cells against oxidative stress induced by 6-OHDA was reported for Drosophila GSTO1. It was shown that GSTO1 loss-of-function mutant flies when subjected to $\mathrm{H}_{2} \mathrm{O}_{2}$ treatment had a decreased survival rate compared to control flies (Lee et al. 2015). The conservation of this oxidative stress protective function suggests that is an important role for GSTO that has been conserved across 500 million years of evolution.

In this study, 8 differentially expressed proteins were identified in SH-SY5Y/hGSTO1 in comparison to SH-SY5Y/control suggesting that many proteins are associated with protection against the 6-OHDA-induced stress (Table 1). Peroxiredoxin (Prx) is an antioxidant enzyme present in organisms from all kingdoms. The enzyme provides a defense against oxidative damage by participating in signaling to control $\mathrm{H}_{2} \mathrm{O}_{2}$ levels 
A

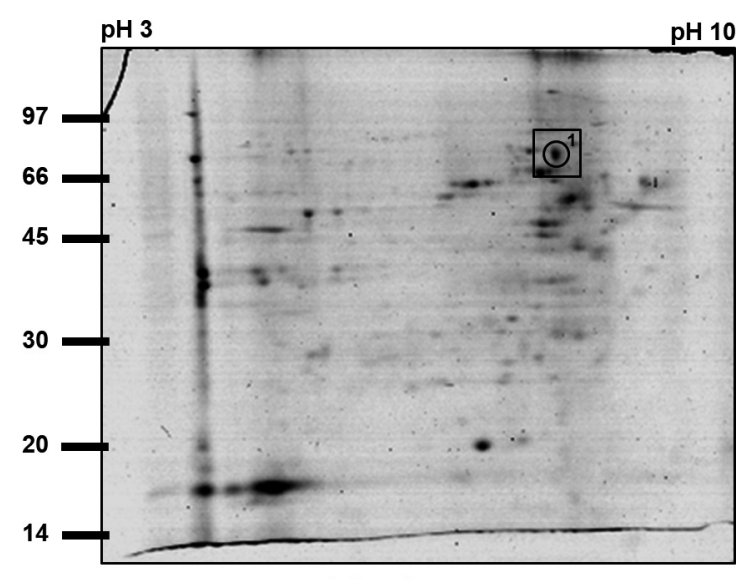

hGSTO1 $0 \mathrm{~min}$

C

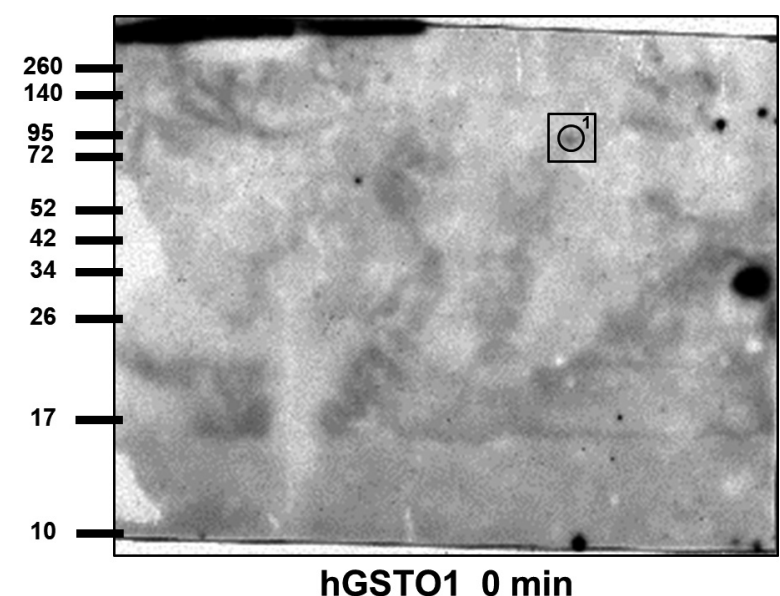

B

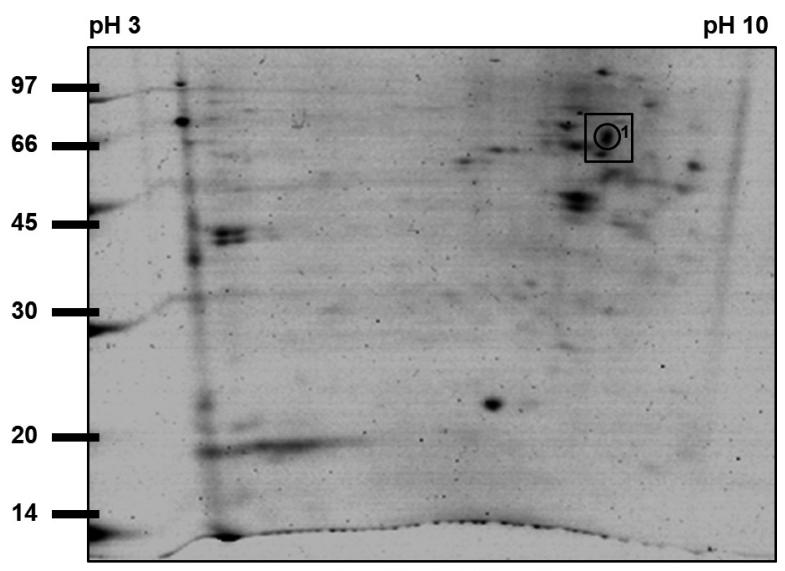

hGSTO1 $30 \mathrm{~min}$

D

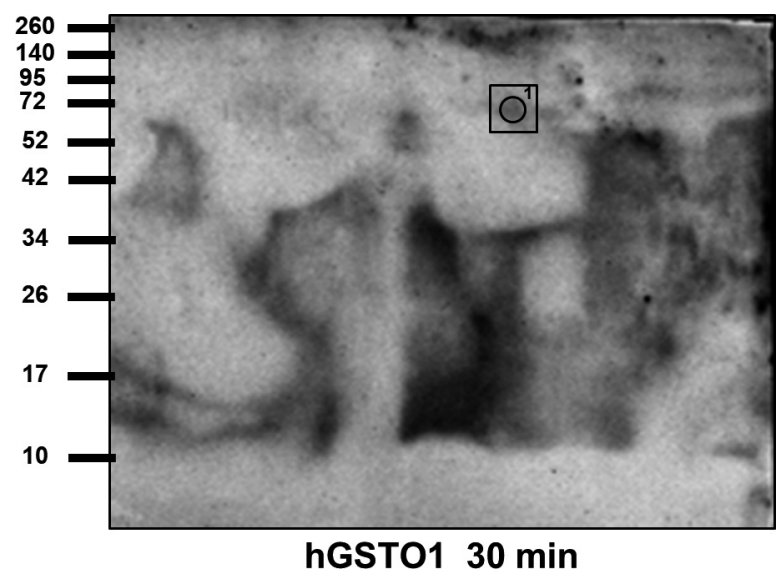

Figure 7. Two-dimension analysis of SH-SY5Y/hGSTO1 untreated (C) and treated (D) with $250 \mu$ M 6-OHDA. One hundred micrograms of protein lysate were separated under non-reducing conditions and immunoblotted with the anti-GSH antibody. Coomassie-stained gels of untreated (A) and treated (B) represent equivalent loading.

(Rhee et al. 2001). Prxs are classified into three classes: typical 2-Cys Prxs, atypical 2-Cys Prxs, and 1-Cys Prxs (Wood et al. 2003). The Prx 2 protein identified in this study is in the 2-Cys Prx subgroup and consists of 199 amino acid residues which are localized in the cytosol. In this study we observed an increased amount of Prx2 in SH-SY5Y/hGSTO1 cells treated with 6-OHDA compared to control. Increasing levels of Prx 2 and the possible Prx2 functions have been reported in many studies of oxidative stress. Over-expression of Prx2 was demonstrated to give neuroprotection against 6-OHDA toxicity in dopamine neurons and preserve motor functions involving the dopamine system in mice (Hu et al. 2011). In addition, Prx2 exhibited anti-apoptotic effects via suppression of ASK-1, JNK/c-Jun and p38 signaling pathway. Moreover, S-nitrosylation of $\operatorname{Prx} 2$ with nitric oxide at two critical cysteines, C51 and C172, was shown to increase SNO-Prx2 in
Parkinson's disease brains and thereby inhibit the enzymatic activity and protective function of Prx 2 for oxidative stress (Fang et al. 2007). Redox status has been shown to induce structural changes in Prx, influence the proteins it binds as well as affect various post translational modifications (Chae et al. 2012). These various changes all contribute to modulating the physiological functions of Prx. Consequently, the hGSTO1induced Prx 2 expression in response to the oxidative stress requires further study.

Vimentin is the most widely expressed intermediate filament protein (Minin and Moldaver 2008). Vimentin is involved in cell migration, cell contact, scaffolding as well as regulation of signal transduction pathways including the MAP kinase ERK pathway (Chernoivanenko et al. 2013). Vimentin expression is significantly higher in Tlymphocytes of patients with Parkinson's disease compared to normal patients (Alberio 
et al. 2014) and has been proposed to be employed as a protein biomarker. In our study, SH-SY5Y/hGSTO1 showed lower expression of vimentin after 6-OHDA treatment. Vimentin was reported to bind phosphorylated ERK upon nerve injury (Perlson et al. 2005). A previous report showed hGSTO1 overexpression appeared to activate the ERK pathway as well as inhibit apoptosis (Piaggi et al. 2010). This would suggest that vimentin is down-regulated to allow the activation of the ERK pathway. Additionally, in the SH-SY5Y/hGSTO1 cells, vimentin itself also undergoes glutathionylation after 30 minutes of 6-OHDA treatment. Glutathionylation of Cys residues, for example in cytoskeletal proteins like the actins, has been reported to protect the proteins against irreversible oxidation (Rokutan et al. 1994). Glutathionylation of vimentin has been reported in several studies (Townsend et al. 2003; Townsend 2007; Xiong et al. 2011). Vimentin possesses only a single cysteine residue at position Cys 328 (Perez-Sala et al. 2015). This residue has a role in filament formation, vimentin network extension and subunit exchange, organelle positioning etc. The modification of the -SH moiety of Cys 328 by glutathionylation appears to be a regulatory switch relevant for protein function by involving a reorganization of the vimentin network in response to electrophilic and oxidative stress. This vimentin Cys residue would be a target of hGSTO1 which has been reported to possess both deglutathionylation and glutathionylation activity which would contribute to cell signaling as well as gene expression through regulation of protein function (Board and Menon 2012, 2013, 2016; Menon and Board 2013; Menon et al. 2014, 2015).

Galectins are $\beta$-galactoside binding proteins which share a common amino acid sequence, the carbohydrate recognition domain (CRD) (Leffler et al. 2002). Both oxidized and reduced forms of Gal-1 are involved in axonal regeneration and the survival, differentiation and synaptic plasticity of neurons via macrophage and astrocyte induction in the neurogeneration mechanism after an injury (Camby et al. 2006). We have found that galectin-1 amounts in SH-SY5Y/ hGSTO1 decreased significantly compared to controls. In contrast, galectin-1 was reported to be up-regulated in human brain tissue from substantia nigra of Parkinson's patients (Werner et al. 2008). After neuronal cell injury by 6-OHDA in our model, the overexpressed hGSTO1 then inhibits the expression of galectin-1. Previous reports and our study taken together suggest that hGSTO1 modulates the expression/function of many proteins some of which also feed into various signaling pathways that play roles in Parkinson's disease. Most likely the modulations occur through the role of hGSTO1 in the glutathionylation cycle for which hGSTO1 has been reported to possess both deglutathionylation and glutathionylation activity (Menon and Board 2013; Menon et al. 2014; Board and Menon 2016). The hGSTO1 is consequently involved in the selective glutathionylation/ deglutathionylation of specific proteins that contribute to cell signaling and regulation, for example $\mathrm{PKC}, \mathrm{NF} \kappa \mathrm{B}$ and several MAPK pathways (Pastore and Piemonte 2012; Popov 2014). Therefore further studies are still needed to elucidate the proteins regulated by hGSTO1 that may serve as molecular targets for the treatment of Parkinson's disease.

Acknowledgements. This work was supported by The National Research Council of Thailand (NRCT), the Thailand Research Fund (IRG5780009), and a grant from Mahidol University.

Conflict of interest. None.

\section{References}

Alberio T, McMahon K, Cuccurullo M, Gethings LA, Lawless C, Zibetti M, Lopiano L, Vissers JP, Fasano M (2014): Verification of a Parkinson's disease protein signature in T-lymphocytes by multiple reaction monitoring. J. Proteome Res. 13, 3554-3561 https://doi.org/10.1021/pr401142p

Board PG (2011): The omega-class glutathione transferases: structure function and genetics. Drug Metab. Rev. 43, 226-235 https://doi.org/10.3109/03602532.2011.561353

Board PG, Coggan M, Chelvanayagam G, Easteal S, Jermiin LS, Schulte GK, Danley DE, Hoth LR, Griffor MC, Kamath AV, et al. (2000): Identification characterization and crystal structure of the omega class glutathione transferases. J. Biol. Chem. 275, 24798-24806 https://doi.org/10.1074/jbc.M001706200

Board PG, Menon D (2013): Glutathione transferases regulators of cellular metabolism and physiology. Biochim. Biophys. Acta 1830, 3267-3288

https://doi.org/10.1016/j.bbagen.2012.11.019

Board PG, Menon D (2016): Structure function and disease relevance of Omega-class glutathione transferases. Arch. Toxicol. 90, 1049-1067 https://doi.org/10.1007/s00204-016-1691-1

Booth J, Boyland E, Sims P (1961): An enzyme from rat liver catalysing conjugations with glutathione. Biochem. J. 79, 516-524 https://doi.org/10.1042/bj0790516

Camby I, Le Mercier M, Lefranc F, Kiss R (2006): Galectin-1: a small protein with major functions. Glycobiology 16, 137R-157R https://doi.org/10.1093/glycob/cwl025

Chae HZ, Oubrahim H, Park JW, Rhee SG, Chock PB (2012): Protein glutathionylation in the regulation of peroxiredoxins: a family of thiol-specific peroxidases that function as antioxidants molecular chaperones and signal modulators. Antioxid. Redox Signal. 16, 506-523

https://doi.org/10.1089/ars.2011.4260

Chernoivanenko IS, Minin AA, Minin AA (2013): Role of vimentin in cell migration. Ontogenez 44, 186-202 (in Russion) https://doi.org/10.1134/S1062360413030016

Dalle-Donne I, Rossi R, Colombo G, Giustarini D, Milzani A (2009): Protein S-glutathionylation: a regulatory device from bacteria to humans. Trends Biochem. Sci. 34, 85-96 https://doi.org/10.1016/j.tibs.2008.11.002

Fang J, Nakamura T, Cho DH, Gu Z, Lipton SA (2007): S-nitrosylation of peroxiredoxin 2 promotes oxidative stress-induced 
neuronal cell death in Parkinson's disease. Proc. Natl. Acad. Sci. USA 104, 18742-18747

https://doi.org/10.1073/pnas.0705904104

Frova C (2006): Glutathione transferases in the genomics era: new insights and perspectives. Biomol. Eng. 23, 149-169 https://doi.org/10.1016/j.bioeng.2006.05.020

Hu X, Weng Z, Chu CT, Zhang L, Cao G, Gao Y, Signore A, Zhu J, Hastings T, Greenamyre JT, Chen J (2011): Peroxiredoxin-2 protects against 6-hydroxydopamine-induced dopaminergic neurodegeneration via attenuation of the apoptosis signalregulating kinase (ASK1) signaling cascade. J. Neurosci. 31, $247-261$ https://doi.org/10.1523/JNEUROSCI.4589-10.2011

Klockgether T (2004): Parkinson's disease: clinical aspects. Cell Tissue Res. 318, 115-120 https://doi.org/10.1007/s00441-004-0975-6

Lee SY, Lim IA, Kang GU, Cha SJ, Altanbyek V, Kim HJ, Lee S, Kim K, Yim J (2015): Protective effect of Drosophila glutathione transferase omega 1 against hydrogen peroxide-induced neuronal toxicity. Gene 568, 203-210 https://doi.org/10.1016/j.gene.2015.05.058

Leffler H, Carlsson S, Hedlund M, Qian Y, Poirier F (2002): Introduction to galectins. Glycoconj. J. 19, 433-440 https://doi.org/10.1023/B:GLYC.0000014072.34840.04

Menon D, Board PG (2013): A role for Glutathione transferase Omega 1 (GSTO1-1) in the glutathionylation cycle. J. Biol. Chem. 288, 25769-25779 https://doi.org/10.1074/jbc.M113.487785

Menon D, Coll R, O'Neill LA, Board PG (2014): Glutathione transferase omega 1 is required for the lipopolysaccharidestimulated induction of NADPH oxidase 1 and the production of reactive oxygen species in macrophages. Free Radical Biol. Med. 73, 318-327

https://doi.org/10.1016/j.freeradbiomed.2014.05.020

Menon D, Coll R, O'Neill LA, Board PG (2015): GSTO1-1 modulates metabolism in macrophages activated through the LPS and TLR4 pathway. J. Cell Sci. 128, 1982-1990 https://doi.org/10.1242/jcs.167858

Minin AA, Moldaver MV (2008): Intermediate vimentin filaments and their role in intracellular organelle distribution. Biochemistry. Biokhimiia 73, 1453-1466 https://doi.org/10.1134/S0006297908130063

Muangpaisan W, Mathews A, Hori H, Seidel D (2011): A systematic review of the worldwide prevalence and incidence of Parkinson's disease. J. Med. Assoc. Thai. 94, 749-755

Paemanee A, Wikan N, Roytrakul S, Smith DR (2016): Application of GelC-MS/MS to proteomic profiling of chikungunya virus infection: Preparation of peptides for analysis. Methods Mol. Biol. 1426, 179-193

https://doi.org/10.1007/978-1-4939-3618-2_16

Pastore A, Piemonte F (2012): S-Glutathionylation signaling in cell biology: Progress and prospects. Eur. J. Pharm. Sci. 46, 279-292 https://doi.org/10.1016/j.ejps.2012.03.010

Perez-Sala D, Oeste CL, Martinez AE, Carrasco MJ, Garzon B, Canada FJ (2015): Vimentin filament organization and stress sensing depend on its single cysteine residue and zinc binding. Nat. Commun. 6, 7287 https://doi.org/10.1038/ncomms8287
Perlson E, Hanz S, Ben-Yaakov K, Segal-Ruder Y, Seger R, Fainzilber M (2005): Vimentin-dependent spatial translocation of an activated MAP kinase in injured nerve. Neuron 45, 715-726 https://doi.org/10.1016/j.neuron.2005.01.023

Piaggi S, Raggi C, Corti A, Pitzalis E, Maschera MC, Saviozzi M, Pompella A, Casini A (2010): Glutathione transferase omega 1-1 (GSTO1-1) plays an anti-apoptotic role in cell resistance to cisplatin toxicity. Carcinogenesis 31, 804-811 https://doi.org/10.1093/carcin/bgq031

Popov D (2014): Protein S-glutathionylation: from current basics to targeted modifications. Arch. Physiol. Biochem. 120, 123-130 https://doi.org/10.3109/13813455.2014.944544

Pringsheim T, Jette N, Frolkis A, Steeves TD (2014): The prevalence of Parkinson's disease: a systematic review and meta-analysis. Mov. Disord. 29, 1583-1590 https://doi.org/10.1002/mds.25945

Rhee SG, Kang SW, Chang TS, Jeong W, Kim K (2001): Peroxiredoxin a novel family of peroxidases. IUBMB Life 52, 35-41 https://doi.org/10.1080/15216540252774748

Rokutan K, Johnston RB, Jr, Kawai K (1994): Oxidative stress induces S-thiolation of specific proteins in cultured gastric mucosal cells. Am. J. Physiol. 266, G247-254 https://doi.org/10.1152/ajpgi.1994.266.2.G247

Simola N, Morelli M, Carta AR (2007): The 6-hydroxydopamine model of Parkinson's disease. Neurotox. Res. 11, 151-167 https://doi.org/10.1007/BF03033565

Townsend DM (2007): S-Glutathionylation: Indicator of cell stress and regulator of the unfolded protein response. Mol. Interventions 7, 313-324 https://doi.org/10.1124/mi.7.6.7

Townsend DM, Tew KD, Tapiero H (2003): The importance of glutathione in human disease. Biomed. Pharmacotherapy 57, 145-155 https://doi.org/10.1016/S0753-3322(03)00043-X

Werner CJ, Heyny-von Haussen R, Mall G, Wolf S (2008): Proteome analysis of human substantia nigra in Parkinson's disease. Proteome Sci. 6, 8 https://doi.org/10.1186/1477-5956-6-8

Whitbread AK, Masoumi A, Tetlow N, Schmuck E, Coggan M, Board PG (2005): Characterization of the omega class of glutathione transferases. Methods Enzymol. 401, 78-99 https://doi.org/10.1016/S0076-6879(05)01005-0

Wongtrakul J, Janphen K, Saisawang C, Ketterman AJ (2014): Interaction of Omega Sigma and Theta glutathione transferases with p38b mitogen-activated protein kinase from the fruit fly Drosophila melanogaster. J. Insect Sci. 14, 60 https://doi.org/10.1673/031.014.60

Wood ZA, Schroder E, Robin Harris J, Poole LB (2003): Structure mechanism and regulation of peroxiredoxins. Trends Biochem. Sci. 28, 32-40 https://doi.org/10.1016/S0968-0004(02)00003-8

Xiong Y, Uys JD, Tew KD, Townsend DM (2011): S-glutathionylation: from molecular mechanisms to health outcomes. Antioxid. Redox Signal. 15, 233-270 https://doi.org/10.1089/ars.2010.3540

Received: September 29, 2017

Final version accepted: December 14, 2017 